
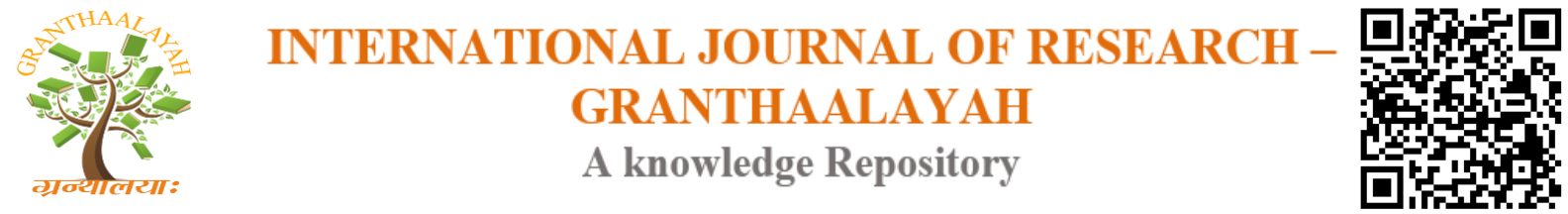

Science

\title{
A REVIEW OF EXPERIMENTAL STUDY AND ANALYSIS OF SPEED CONTROL OF PERMANENT MAGNET AND WOUNDED TYPE DC MOTOR
}

\author{
Tanu Mahobia ${ }^{1}$, Dr. A. K. Kori ${ }^{2}$ \\ ${ }^{1}$ M.E. Student (High Voltage Engg.) ,Department of Electrical Engineering Jabalpur \\ Engineering College, Jabalpur (M.P) 482011, INDIA \\ ${ }^{2}$ Associate Professor, Department of Electrical Engineering Jabalpur Engineering College, \\ Jabalpur (M.P) 482011, INDIA
}

DOI: https://doi.org/10.29121/granthaalayah.v4.i9.2016.2549

\section{ABSTRACT}

The permanent magnet DC motors are used in various applications as heater, wiper and personal computer. A DC motor is any of a class of electrical machines that converts direct current electrical power into mechanical power. The most common types rely on the forces produced by magnetic fields. Nearly all types of DC motors have some internal mechanism, either electromechanical or electronic; to periodically change the direction of current flow in part of the motor. Most types produce rotary motion; a linear motor directly produces force and motion in a straight line.

Keywords:

Rectifier, Permanent Magnet DC Motor, wounded type DC Motor.

Cite This Article: Tanu Mahobia, Dr. A. K. Kori, “A REVIEW OF EXPERIMENTAL STUDY AND ANALYSIS OF SPEED CONTROL OF PERMANENT MAGNET AND WOUNDED TYPE DC MOTOR" International Journal of Research - Granthaalayah, Vol. 4, No. 9 (2016): 151-156.

\section{INTRODUCTION}

A rectifier is an electrical device that converts alternating current (AC), which periodically reverses direction, to direct current (DC), which flows in only one direction. The process is known as rectification. Physically, rectifiers take a number of forms, including vacuum tube diodes, mercury-arc valves, copper and selenium oxide rectifiers, semiconductor diodes, silicon-controlled rectifiers and other silicon-based semiconductor switches. Historically, even synchronous electromechanical switches and motors have been used. Early radio receivers, called crystal radios, used a "cat's whisker" of fine wire pressing on a crystal of galena (lead sulfide) to serve as a point-contact rectifier or "crystal detector". 


\section{RECTIFIER DEVICES}

Before the development of silicon semiconductor rectifiers, vacuum tube thermionic diodes and copper oxide- or selenium-based metal rectifier stacks were used. With the introduction of semiconductor electronics, vacuum tube rectifiers became obsolete, except for some enthusiasts of vacuum tube audio equipment. For power rectification from very low to very high current, semiconductor diodes of various types (junction diodes, Schottky diodes, etc.) are widely used.

\section{RECTIFIER CIRCUITS}

Rectifier circuits may be single-phase or multi-phase (three being the most common number of phases). Most low power rectifiers for domestic equipment are single-phase, but three-phase rectification is very important for industrial applications and for the transmission of energy as DC (HVDC).

\section{SINGLE-PHASE RECTIFIERS}

\section{HALF-WAVE RECTIFICATION}

In half wave rectification of a single-phase supply, either the positive or negative half of the AC wave is passed, while the other half is blocked. Because only one half of the input waveform reaches the output, mean voltage is lower. Half-wave rectification requires a single diode in a single-phase supply, or three in a three-phase supply. Rectifiers yield a unidirectional but pulsating direct current; half-wave rectifiers produce far more ripple than full-wave rectifiers, and much more filtering is needed to eliminate harmonics of the AC frequency from the output.
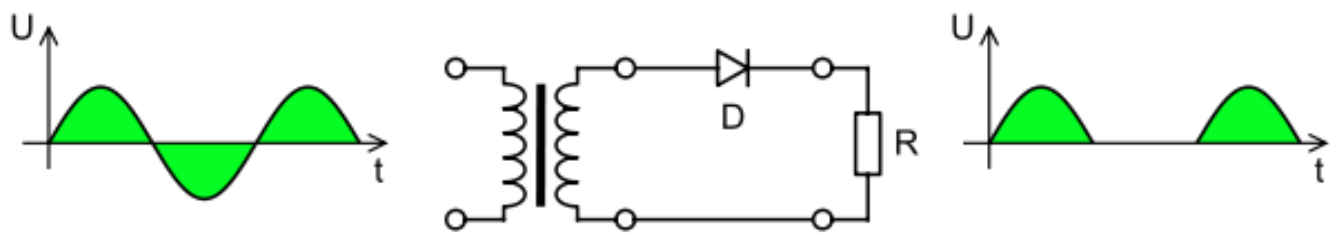

Figure 1: Half-wave rectifier

\section{FULL-WAVE RECTIFICATION}

A full-wave rectifier converts the whole of the input waveform to one of constant polarity (positive or negative) at its output. Full-wave rectification converts both polarities of the input waveform to pulsating DC (direct current), and yields a higher average output voltage. Two diodes and a center tapped transformer, or four diodes in a bridge configuration and any AC source (including a transformer without center tap), are needed. ${ }^{[3]}$ Single semiconductor diodes, double diodes with common cathode or common anode, and four-diode bridges, are manufactured as single components. 

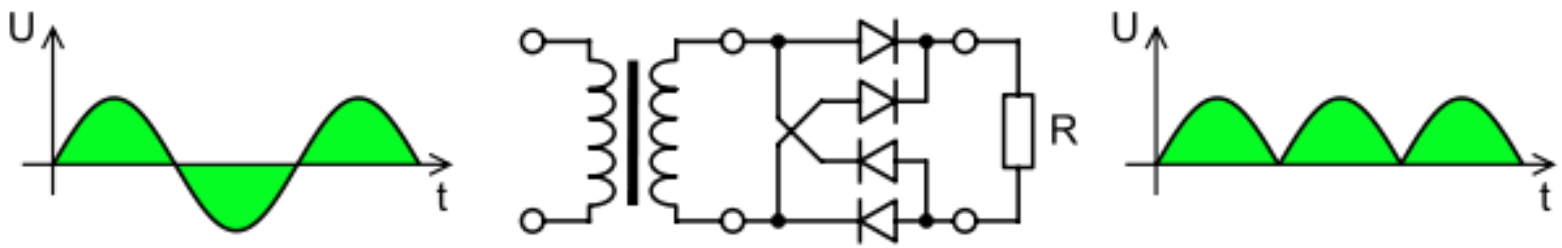

Figure 2: full-wave rectifier using 4 diodes.

For single-phase AC, if the transformer is center-tapped, then two diodes back-to-back (cathodeto-cathode or anode-to-anode, depending upon output polarity required) can form a full-wave rectifier. Twice as many turns are required on the transformer secondary to obtain the same output voltage than for a bridge rectifier, but the power rating is unchanged.
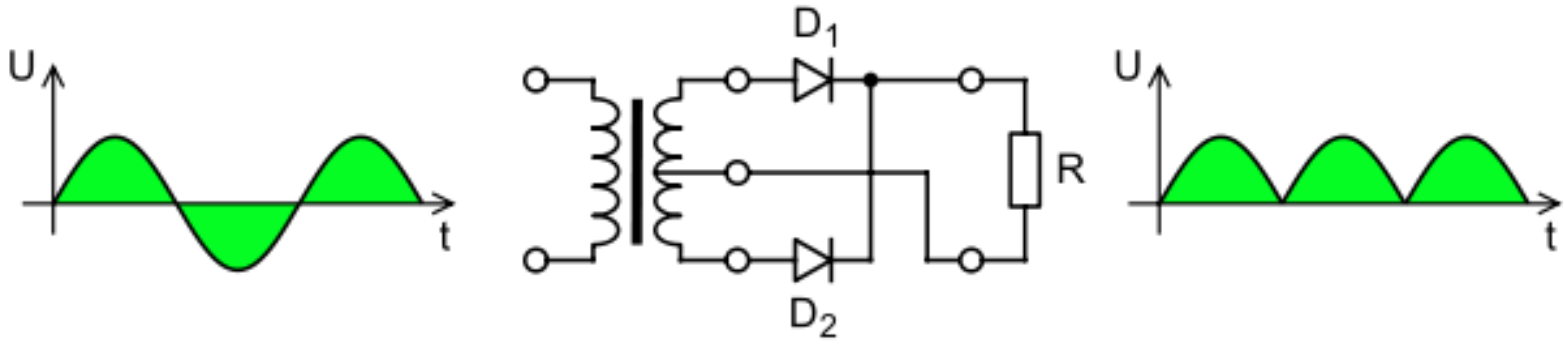

Figure 3: Full-wave rectifier using a center tap transformer and 2 diodes.

\section{MOTOR}

DC motors were the first type widely used, since they could be powered from existing directcurrent lighting power distribution systems. A DC motor's speed can be controlled over a wide range, using either a variable supply voltage or by changing the strength of current in its field windings. Small DC motors are used in tools, toys, and appliances. The universal motor can operate on direct current but is a lightweight motor used for portable power tools and appliances. Larger DC motors are used in propulsion of electric vehicles, elevator and hoists, or in drives for steel rolling mills. The advent of power electronics has made replacement of DC motors with AC motors possible in many applications.

\section{ELECTROMAGNETIC MOTORS}

A coil of wire with a current running through it generates an electromagnetic field aligned with the center of the coil. The direction and magnitude of the magnetic field produced by the coil can be changed with the direction and magnitude of the current flowing through it.A simple DC motor has a stationary set of magnets in the stator and an armature with one or more windings of insulated wire wrapped around a soft iron core that concentrates the magnetic field.

The windings usually have multiple turns around the core, and in large motors there can be several parallel current paths. The ends of the wire winding are connected to a commutator. The commutator allows each armature coil to be energized in turn and connects the rotating coils with the external power supply through brushes. (Brushless DC motors have electronics that switch the DC current to each coil on and off and have no brushes.) 
The total amount of current sent to the coil, the coil's size and what it's wrapped around dictate the strength of the electromagnetic field created. The sequence of turning a particular coil on or off dictates what direction the effective electromagnetic fields are pointed. By turning on and off coils in sequence a rotating magnetic field can be created. These rotating magnetic fields interact with the magnetic fields of the magnets (permanent or electromagnets) in the stationary part of the motor (stator) to create a force on the armature which causes it to rotate. In some DC motor designs the stator fields use electromagnets to create their magnetic fields which allow greater control over the motor.

Different number of stator and armature fields as well as how they are connected provide different inherent speed/torque regulation characteristics. The speed of a DC motor can be controlled by changing the voltage applied to the armature. The introduction of variable resistance in the armature circuit or field circuit allowed speed control. Modern DC motors are often controlled by power electronics systems which adjust the voltage by "chopping" the DC current into on and off cycles which have an effective lower voltage.

\section{BRUSHED}

The brushed DC electric motor generates torque directly from DC power supplied to the motor by using internal commutation, stationary magnets (permanent or electromagnets), and rotating electrical magnets. Advantages of a brushed DC motor include low initial cost, high reliability, and simple control of motor speed. Disadvantages are high maintenance and low life-span for high intensity uses. Maintenance involves regularly replacing the carbon brushes and springs which carry the electric current, as well as cleaning or replacing the commutator. These components are necessary for transferring electrical power from outside the motor to the spinning wire windings of the rotor inside the motor. Brushes consist of conductors.

\section{BRUSHLESS}

Typical brushless DC motors use one or more permanent magnets in the rotor and electromagnets on the motor housing for the stator. A motor controller converts DC to AC. This design is mechanically simpler than that of brushed motors because it eliminates the complication of transferring power from outside the motor to the spinning rotor. The motor controller can sense the rotor's position via Hall effect sensors or similar devices and can precisely control the timing, phase, etc., of the current in the rotor coils to optimize torque, conserve power, regulate speed, and even apply some braking. Advantages of brushless motors include long life span, little or no maintenance, and high efficiency.

\section{PERMANENT MAGNET STATORS}

A PM motor does not have a field winding on the stator frame, instead relying on PMs to provide the magnetic field against which the rotor field interacts to produce torque. Compensating windings in series with the armature may be used on large motors to improve commutation under load. Because this field is fixed, it cannot be adjusted for speed control. PM fields (stators) are convenient in miniature motors to eliminate the power consumption of the field winding. Most larger DC motors are of the "dynamo" type, which have stator windings. Historically, PMs could 
not be made to retain high flux if they were disassembled; field windings were more practical to obtain the needed amount of flux. However, large PMs are costly, as well as dangerous and difficult to assemble; this favors wound fields for large machines.

\section{WOUND STATORS}

There are three types of electrical connections between the stator and rotor possible for DC electric motors: series, shunt/parallel and compound (various blends of series and shunt/parallel) and each has unique speed/torque characteristics appropriate for different loading torque profiles/signatures.

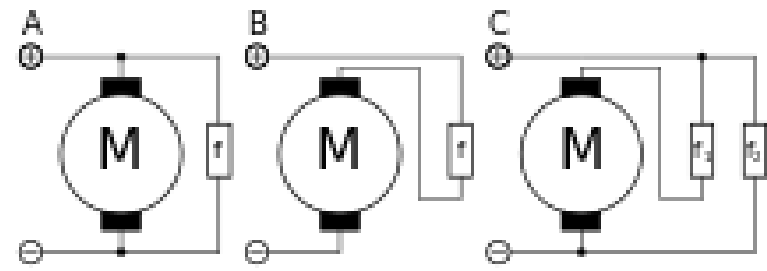

Figure 4: A field coil are connected in shunt, in series, or in compound with the armature of a DC machine

\section{LITERATURE REVIEW}

Amit Solanki (2014)- This paper deals with the analysis and Simulation of Single-phase fullwave ac to dc converter analysed on the basis of performing parameters and simulated with different types of loads. A Simulation Result, which includes a study of performance parameters like ,PF, FF, Vavg, Vrms, Iavg, ,Irms and Efficiency etc. agree with the theoretical results .the development of model is useful for computer aided analysis and design of full converter including firing circuits.

Robinson P. (2014)- The use of tool like MATLAB-SIMULINK has always been a useful for researcher and the designer for analyzing and designing different circuits. The paper demonstrate the performance comparison of single and $3-\varnothing$ rectifier circuits in term of its output voltage , current and possible maximum and minimum firing angle. Power Electronics includes the use of different electronics components \& its structure, characteristic and application circuit, which can withstand large voltage and current. Due to the withstand capability at high voltage and current, this devices are used in industry for control application. The single and $3-\varnothing$ uncontrolled and controlled rectifiers with R, RL load (with and without freewheeling diode); choppers; inverters; $\mathrm{AC}$ voltage regulator are one of them.

S. Raghuwanshi (2012)- Power Electronics is interdisciplinary and is at the confluence of three fundamental technical areas - power, electronics and control, and is used in a wide variety of industries from computers, chemical plants to rolling mills. The importance of power electronics has grown over the years due to several factors. Computer simulation can greatly aid in the analysis, design and education of Power Electronics. A computer simulation (or "sim") is an attempt to model a real-life or hypothetical situation on a computer so that it can be studied to see how the system works. By changing variables, predictions may be made about the behavior of the system. In our work towards this we have ensured to bring out the different responses of current and voltage in the power electronic circuits. 
Rohit Gupta (2012)- Half converter, semi converter, full converter and dual converter are some of the thyristor based circuits which are used for speed control of DC motor. This paper studies different speed control techniques of DC motor and makes a comparative study of different converter based speed controller techniques. There are many methods of speed control of DC drives namely field control, armature voltage control and armature resistance control methods . DC motors provide high starting torque which is required for traction applications. In DC motor control over a large speed range, both below and above the rated speed can be achieved quite easily. DC motors have inherent disadvantages that it needs regular maintenance and it is bulky in size. DC motors are tailor made, so it is very difficult to replace them. In general, armature voltage control method is widely used to control the DC drives. In this method, a controlled rectifier, or chopper is used but due involvement of power electronics elements, nonlinear torque speed characteristics are observed which are undesirable for control performance.

\section{REFERENCES}

[1] Powerex Inc., FT1500AU-240 Ultra high voltage thyristor, Powerex Data Sheet.

[2] R.W. Wall and H.L. Hess, Design and microcontroller implementation of a three-phase SCR power converter, Idaho University, Department of Electrical Engineering

[3] Mehran Mirjafari, Robert S. Balog, Multi-objective design optimization of renewable energy system inverters using a Descriptive language for the components, Applied Power Electronics Conference and Exposition (APEC), 2011 Twenty-Sixth Annual IEEE, pp. $1838-1845$.

[4] F. Blaabjerg, F. Iov, T. Kerekes, R. Teodorescu, ,Trends in power electronics and control of renewable energy systems, Power Electronics and Motion Control Conference (EPE/PEMC), 2010, pp. K-1 - K-19.

[5] Maria IMECS, Csaba SZABO, Ioan Iov INCZE, Modeling and simulation of controlled bi-directional power electronic converters in a DC energy distribution line with AC gridand motor-side active filtering, Power Electronics and Applications, 2007 ,pp.1-10.

[6] R.S. Ramshaw, Power Electronics Semiconductor Switches (Chapman \& Hall, London, 1993).

[7] P.C. Sen, Power Electronics (Tata McGraw-Hill, 1988).

[8] J. Schaefer, Rectifier Circuits: Theory and Design (Wiley, 1965).

[9] G.J. Wakileh, Power Systems Harmonics (Springer, 2001).

[10] M.H. Rashid (ed.), Power Electronics Handbook (Academic Press, 2001)

[11] A.W. Kelley and W.F. Yadusky, Phase-controlled rectifier linecurrent harmonics and power factor as a function of firing angle and output filter inductance, Proc. APEC'90.

[12] Eupec, Rectifier diode D 2601N, BIP AC / SM PB, 2002-05-31, Eupec Data Sheet.

[13] Eupec, Phase control thyristor T 2871N, BIP AM / SM PB, 2002-04- 07, Eupec Data Sheet. 